\title{
Tourism and Electricity Consumption in 9 European Countries: A Decomposition Analysis Approach
}

María del P. Pablo-Romero, Antonio Sánchez-Braza, and Javier Sánchez-Rivas

\section{María del P. Pablo-Romero}

Department of Economic Analysis and Political Economy

Faculty of Economics and Business Sciences

Universidad de Sevilla

Ramón y Cajal 1, 41018 Seville, Spain

Tel.: +34 954557 611. Fax: +34954557629

mpablorom@us.es

Antonio Sánchez-Braza (corresponding author)

Department of Economic Analysis and Political Economy

Faculty of Economics and Business Sciences

Universidad de Sevilla

Ramón y Cajal 1, 41018 Seville, Spain

Tel.: +34 954557 529. Fax: +34954 557629

asb@us.es

\section{Javier Sánchez-Rivas}

Department of Economic Analysis and Political Economy

Faculty of Economics and Business Sciences

Universidad de Sevilla

Ramón y Cajal 1, 41018 Seville, Spain

Tel.: +34 954557 524. Fax: +34 954554629

sanchezrivas@us.es

\section{Acknowledgements}

The authors wish to acknowledge the funding provided by the following institutions: the RTI2018-096725-B-I00 Project of the Spanish Ministry of Ministry of Science, Innovation and Universities; the "Cátedra de Economía de la Energía y del Medio Ambiente" sponsored by "Red Eléctrica de España" at the "Universidad de Sevilla" (University of Seville); the Andalusian Regional Government (Project SEJ-132); and the "Departamento de Análisis Económico y Economía Política (Universidad de Sevilla)" (Department of Economic Analysis and Political Economy at the University of Seville). 


\title{
Tourism and Electricity Consumption in 9 European Countries: A Decomposition Analysis Approach
}

\begin{abstract}
Tourism is a major economic activity constituting one of the main sectors in economic terms. European countries traditionally play a significant role in the overall international tourism flow. However, while tourism has a noticeable positive impact on economic development, it also contributes to environmental degradation by increasing energy consumption and therefore emissions.
\end{abstract}

This paper analyses the relationships between Hotel and Restaurant electricity consumption and tourism growth in 9 European countries during 2004-2012, for which there is a sufficient amount of data available. A decomposition analysis based on logmean Divisia index method (LMDI I) is conducted to examine electricity consumption on this sector and their components. Five decomposition factors are considered: energy intensity (EI), physical capital intensity $(K I)$, physical and human capital relationship $(K L)$, human capital intensity $(L I)$ and the tourism factor $(T)$. Results show the evolution of energy consumption related to this sector, identifying the driving forces that have influenced it.

Keywords: Tourism growth, electricity consumption, Hotels and Restaurants sector, European countries, LMDI, decomposition analysis. 


\section{Introduction}

The tourism sector is a major economic activity in the world. Its total contribution to GDP was USD 7,613.3bn, representing 10.2\% of GDP and 9.6\% of total employment (World Travel \& Tourism Council, 2017). Thus, the tourism sector constitutes one of the main sectors in economic terms for the most developed or developing countries, being one of the largest generators of employment in the world. According to the European Commission, tourism is the third largest socio-economic activity in the EU (after the trade and distribution, and construction sectors), and has an overall positive impact on economic growth and employment (Nižić, Grdić \& Hustić, 2016). Traditionally, Europe plays a significant role in the overall international tourism flow. International tourist arrivals (overnight visitors) in 2016 grew by $3.9 \%$ to reach a total of 1,235 million worldwide, which equates to an increase of 46 million over the previous year. In this context, Europe welcomed 616 million international tourists, equivalent to half the world total, an increase of 13 million from 2015 (United Nations World Tourism Organization, 2017).

However, while tourism has a noticeable positive impact on economic development, improving the balance of payments, boosting investments and generating employment, it also contributes to environmental degradation by increasing $\mathrm{CO}_{2}$ emissions, mainly through the sectoral energy consumption. In the same vein, studies such as those by Scott, Hall, and Gössling (2016a, 2016b), and Scott, Gössling, Hall, and Peeters (2016) analyse the effect of tourism in the Climate Change and the implication of the Paris Agreement (COP 21) for the sector, including impacts and mitigation and adaptation policies (United Nations, 2015). So, while energy, labour and capital resources are used to produce desirable goods and services through economic activities, they simultaneously produce undesirable outputs such as GHG emissions (International 
Panel on Climate Change, 2014; Moutinho, Madaleno \& Silva, 2016). Thus, the increase in the number of tourists not only contributes to the economic welfare of the country but also to its energy consumption (Katirciogulu, 2014). In this sense, tourism also needs to be considered from the viewpoint of energy consumption and $\mathrm{CO}_{2}$ emissions, being considered as a new field of study (Frantál \& Urbánková, 2017).

Regarding energy consumption, some papers focus on the energy use associated with global tourism or derived from specific tourism activities or services. Among the first ones, Gössling (2002) calculated that the use of energy associated with global tourism in 2000 was 14,000 PJ, while Rutty, Gössling, Scott, and Hall (2015) update these data, indicating that energy associated with global tourism was equal to 17,500 PJ in 2005. Among the second ones, it is worth highlighting the studies by Becken, Frampton and Simmons (2001), and Becken, Simmons and Frampton (2003) which analyse the energy use within the accommodation sector and associated with different tourist travel choices, respectively. Likewise, more recently, some papers have pointed out the relationships between energy consumption, tourism and growth (for example, Dogan \& Aslan, 2017; and Nepal, al Irsyad \& Nepal, 2019), some of them also considering different specifications of the Environmental Kuznets curves (for example, Naradda Gamageet, Hewa Kuruppuge, \& Haq, 2017; Pablo-Romero, Pozo-Barajas, \& SánchezRivas, 2017, and Pablo-Romero, Sánchez-Braza, \& Sánchez-Rivas, 2017).

Following on from these previous studies, the aim of this paper is to analyse the relationships between Hotel and Restaurant electricity consumption and tourism growth in 9 European countries for the period 2004-2012, for which there is a sufficient amount of data available. In order to reach this objective, in this study we propose using the logmean Divisia index method (LMDI I) decomposition technique (Ang, 2005) to quantitatively evaluate the performance of electricity consumption in the Hotels and 
Restaurants sector for the 9 European countries considered. As far as our knowledge is concerned, this technique is the first time it has been used to assess the extent to which tourism and other productive factors affect or determine energy consumption in the tourism sector; specifically, in this study, the electricity consumption of the hospitality sector.

Essentially, IDA is an analytical tool designed to quantify the driving forces influencing changes in an aggregate indicator as energy consumption. Such a method may be easily applied to any source of available data at any aggregation level in a given time period. Proposed decomposition factors in this study, include the energy intensity factor $(E I)$, the physical capital intensity factor $(K I)$, the physical and human capital relationship factor $(K L)$, the human capital intensity factor $(L I)$ and the tourism factor $(T)$.

The paper is structured in five sections. After the Introduction, in Section 2, the methodology is presented and the factors proposed to identify, quantify and explain the determinant of the evolution for Hotel and Restaurant electricity consumption are justified. In Section 3 data are presented, while in Section 4 the decomposition analysis results are presented and discussed. Finally, Section 5 provides a conclusion.

\section{Methodology}

Studies based on LMDI I are useful for understanding the evolution of energy consumption related to this sector and identifying the driving forces that have impacted these possible changes and evolution, as well as the importance of these variables in the energy consumption of this sector. In this sense, this study follows the criteria of Ang (2004), who evaluated the various decomposition methods. He concluded that LMDI I is a more recommendable method than others thanks to both its theoretical base and its set of properties, which are satisfactory in the case of index decomposition. 
LMDI I is a "refined" non-parametric IDA (Index Decomposition Analysis) approach based on the Divisia index method, with weighted logarithmic mean. An additional argument that favours LMDII is that it allows perfect decomposition (that is, without residuals) and provides a simple and direct association between the additive and the multiplicative decomposition form (Ang \& Liu, 2007).

Recent studies using this methodology to analyse energy consumption growth are numerous; referring to different countries, groups of countries and economic sectors. Among these studies, it is worth highlighting those carried out by Chong et al. (2017), Cruz and Dias (2016), Dong, Zhang, Mu, and Su (2016), Ediger and Huvaz (2006), Lima, Nunes, Cunha, and Lucena (2017), and Liu, Zhou, Zhou, and Wang (2018) who referred to the whole economy; those by Duran, Aravena, and Aguilar (2015), Olanrewaju, Jimoh, and Kholopane (2012), and Wang, Ge, Liu, and Ding, (2016) who referred to the industrial sectors and that by Zhang, Song, Li, and $\mathrm{Li}$ (2016) who referred to the residential one. Nevertheless, in spite of the recent growth of this technique used in the explanation of the factors affecting energy consumption, to our knowledge there are no previous studies referring to the tourism sector or some specific tourist related sector; although some previous studies have used this technique to analyse the factors affecting the generation of emissions related to the sector (RobainaAlves, Moutinho, and Costa, 2016, for example).

Likewise, it is worth noting that there is no unique expression of factor decomposition for the energy consumption, but different expressions are used depending on the study. Nevertheless, three main types of factors are being incorporated in the previous studies; related to the energy efficiency, to the activity level and more recently, as in Liu et al. (2018), to the production function factors. 
Based on these three types of factors, in this study, five factors have been proposed to identify, quantify and explain the main determinant of the evolution for Hotel and Restaurant electricity consumption $E I, K I, K L, L I$ and $T$. Applying the decomposition proposed to $n$ European countries considered, the total electricity consumption for this sector may be presented as follows:

$$
E=\sum_{i=1}^{n} \frac{E_{i}}{G A V_{i}} \frac{G A V_{i}}{K_{i}} \frac{K_{i}}{L_{i}} \frac{L_{i}}{\text { Tur }_{i}} \text { Tur }_{i}
$$

Where $E_{i}$ represents the electricity consumption of the Hotels and Restaurants sectorof country $i$; $G A V_{i}$ represents the Gross Added Value registered for this sector of country $i$; $K_{i}$ denotes the capital stock for this sector of country $i, L_{i}$ indicates the employment level for this sector of country $i$ measured as the number of hours worked, and $T_{i}$ represents the nights spent at tourist accommodation establishments, as a measure of tourism level of country $i$.

So, incorporating the five factors proposed, Equation [1] may be expressed as:

$$
E=\sum_{i=1}^{n} E I_{i} \quad K I_{i} \quad K L_{i} \quad L I_{i} T_{i}
$$

The energy intensity factor $(E I)$ corresponds to the ratio of electricity consumption and GAV for the Hotels and Restaurants sector in a given period for each country, representing the energy required in comparison to the output in this sector. EI factor is often used as a measure or aggregate proxy of the energy efficiency level of a country's economy or sector; as EI grows, energy efficiency decreases. It may be seen as a signal indicating the efficiency of the energy system, technology choices, energy prices, energy conservation techniques and investments for energy saving in this sector (Goldemberg \& Johansson, 2004; Voigt, De Cian, Schymura, \& Verdolini, 2014). 
The physical capital intensity factor $(K I)$, the physical and human capital relationship factor $(K L)$ and the human capital intensity factor $(L I)$ represent the way in which the productive activity of the sector affects the energetic consumption. In this sense, recent studies, such as that of Du and Lin (2015), indicate that capital and labour may have relevant substitution effects on energy consumption. The ratio of GAV and the stock of physical capital for the Hotels and Restaurants sector in a given period denotes the capitalization level of this sector for each country, as an indicator of capital productivity. In this sense, several previous studies have highlighted the role of the stock of capital on energy consumption, indicating in some cases, as in Pablo-Romero and Sánchez-Braza (2015), that energy is weakly substitutable with this factor. In other recent studies, increasing stock of capital tends to show an increase in energy use, such as that of in Saidi and Hammami (2015).

The ratio of the stock of physical capital and the number of hours worked for the Hotels and Restaurants sector in a given period for each country, indicates the private physical capital stock level per employee hour. This ratio, according to Wu (2012), indicates how the productive structure may affect the energy efficiency, being considered a proxy of the level of technology involved.

The human capital intensity factor $(L I)$ denotes the ratio of the number of hours worked for the Hotels and Restaurants sector and the overnight stays for each country, as an indicator of the intensity of labour requirements of this sector.

Finally, the tourism factor $(T)$ represents the total number of overnight stays. It is considered as a measure of tourism, therefore is assessed as nights spent at tourist accommodation establishments, which include hotels, holiday and other short-stay accommodation, camping grounds, recreational vehicle parks and trailer parks. Total overnight stays have been used before as a proxy to measure tourism, such as in the 
studies by Cortes-Jimenez and Pulina (2010), Gómez-Calero, Molina, and PabloRomero (2014), and more recently in the study by Pablo-Romero et al. (2017a, 2017b). Therefore, this indicator represents the sectoral level of activity, which is always included in previous studies by different indicators depending on the study in question.

Changes in the electricity consumption of the Hotels and Restaurants sector may be assessed by implementing additive or multiplicative decomposition. In this paper, an additive LMDII analysis is carried out. The overall ratio of change in electricity consumption from one period to another may be decomposed as the sum of the considered factors:

$$
\Delta E=E_{t}-E_{t-1}=\Delta E I+\Delta K I+\Delta K L+\Delta L I+\Delta T
$$

With the right-hand side variables being the representatives of the various contributing determinants as previously defined but now being referred to as changes, and where:

$$
\begin{gathered}
\Delta E I=\sum_{i=1}^{n} w_{i,(t)} \ln \frac{E I_{i,(t)}}{E I_{i,(t-1)}} \\
\Delta K I=\sum_{i=1}^{n} w_{i,(t)} \ln \frac{K I_{i,(t)}}{K I_{i,(t-1)}} \\
\Delta K L=\sum_{i=1}^{n} w_{i,(t)} \ln \frac{K L_{i,(t)}}{K L_{i,(t-1)}} \\
\Delta L I=\sum_{i=1}^{n} w_{i,(t)} \ln \frac{L I_{i,(t)}}{L I_{i,(t-1)}} \\
\Delta T=\sum_{i=1}^{n} w_{i,(t)} \ln \frac{T_{i,(t)}}{T_{i,(t-1)}}
\end{gathered}
$$


the term $w_{i,(t)}$ is the estimated weight for the additive LMDII method and is defined as Ang (2005):

$$
w_{i,(t)}=\frac{E_{i,(t)}-E_{i,(t-1)}}{\ln E_{i,(t)}-\ln E_{i,(t-1)}}
$$

\section{Data}

This study covers the 9 European countries considered and the time period from 2004 to 2012, depending on the electricity consumption of the Hotels and Restaurants sector and Gross Value Added (GVA) availability data. The European countries for which there are available data are the following: Denmark, France, Germany, Italy, Netherlands, Portugal, Spain, Sweden, and the United Kingdom. This period was chosen as it coincides with the available database related to the Hotels and Restaurants sector.

Hotel and Restaurant electricity consumption data came from the Odyssee European Energy Efficiency Database (Enerdata, 2018) published by Enerdata, which offers information about energy consumption by sectors. The energy consumption of the service sector is divided into 8 branches, being one of them Hotels and Restaurants which corresponds to Section I of the International Standard Industrial Classification (ISIC) of economic activities. It covers electricity consumption in the provision of short-stay accommodation for visitors and other travellers and the provision of complete meals and drinks fit for immediate consumption. In this study, figures are expressed in thousand tons of oil equivalents (ktoe).

GAV data for the Hotels and Restaurants sector by countries also came from the Odyssee database (Enerdata, 2018). Figures are expressed in millions of 2005 constant Euros. 
Tourism data came from the Eurostat database (Eurostat, 2018). In this study, total overnight stays are considered as a measure of tourism, therefore this is measured as nights spent at tourist accommodation establishments, which include hotels, holiday and other short-stay accommodation, camping grounds, recreational vehicle parks and trailer parks. Figures are expressed in overnight stays.

Finally, physical capital and employment data for the Hotels and Restaurants sector by country come from the WIOD database (WIOD, 2018). The WIOD database, in the WIOD Socio Economic Accounts sub-base, provides data on labour and capital inputs at the industry level. The capital data included investment and capital stocks series by countries. The figures have been considered in millions of 2005 constant Euros. Information about employment gathers different employment data, such as hours worked and number of employed individuals, among other data. The data used in this study is the number of hours worked, formulated in millions of hours.

\section{Decomposition analysis results}

Figure 1 shows the main results shown by the LMDI analysis for the 2004-2012 period, for which a complete database for all considered countries has been drafted for all of the factors considered. Positive values imply that the factor or effect acts as a driver of the electricity consumption of the Hotels and Restaurants sector (measured in ktoe in Figure 1). When its sign is negative, this reveals that it works as a compensating factor.

\section{Insert Figure 1 here}

Figure 1. Main figures for factors considered in LMDI analysis 2004-2012 for all countries. 
Three main facts may be highlighted initially from Figure 1. Firstly, there is no homogeneous behaviour within the period, so different factors induce the electricity consumption each year. Secondly, there is a notable change in the energy consumption around the financial crisis years, with a high energy intensity factor value, which may be explained by a high sectoral GVA decrease in these years. Finally, it is also relevant to highlight the importance of the tourist factor, i.e. activity factor, to explain the electricity consumption. Over the years, tourism grows and acts as a driving factor, while during the crisis, when tourism decreases; it acts as a compensating factor.

\subsection{Main results by factors.}

These general results can be specified by showing the obtained results for the five decomposition factors, detailed by country and year. Table A.1 in Annex shows the main figures for each considered factor in the LMDI-I analysis for the period 2004-2012, in total terms and by countries, while Figure 2 represents the evolution of the five considered factors for the 9 countries from 2004 to 2012.

The energy intensity factor $(E I)$, as shown in Figure 2, shows a fairly homogeneous behaviour among countries. In general, its value is negative in all periods except in the financial crisis years, when it becomes positive in all countries. Therefore, this factor has reduced electricity consumption, except in the years 2007-2009. During the financial crisis, the reduction of tourist revenues has not been accompanied by a reduction in energy consumption, which may highlight the difficulty for catering establishments to reduce their energy consumption when establishments are not full, or their occupation level is low. It is also worth noting the high influence of this factor in relation to the other ones considered in this study on energy consumption, especially during the crisis years. 


\section{Insert Figure 2 here}

Figure 2. Main figures for factors considered in LMDI analysis 2004-2012 detailed by countries.

Regarding the physical capital intensity factor $(K I)$, it is observed in Figure 2 that the productivity of physical capital led to the reduction of energy consumption from 2004 to 2009. Since then it has been positive, probably caused by a more intensive use of the stock of capital. In this sense, it is worth noting that after the financial crisis, no capital has been invested in the sector due to the uncertainty of previous years, being also possible that these investments require some time to be carried out.

In any case, capital investments have not been undertaken at the same speed as the sectoral GVA growth. The lack of investment in capital can in turn be the cause of a scarce investment in efficient energy systems, which are usually associated with new capital investments, which does not allow for a reduction in energy consumption as activity increases.

The physical and human capital relationship factor $(K L)$ has been considered by some authors (for example, $\mathrm{Wu}, 2012$ ) as a proxy of the level of technology involved in the productive process, showing the tourist sector structural relationships between fixed and variable factors. The results show that before the financial crisis, activity growth was accompanied by fixed factor growth, i.e. by capital investments driving energy consumption. During the crisis, the sector adaptation has involved the reduction of the variable factor, without reducing the fixed factor. Once the sector activity starts growing again, by increasing for example the tourist overnight stays, the fixed factor does not grow (stock of capital), but the variable one (human factor) increases, acting as a 
compensating energy consumption factor. Nevertheless, it is worth noting that this adaptation is quite heterogeneous by countries.

Finally, it is worth noting the influence of the human capital intensity factor $(L I)$ and the tourism factor $(T)$. In general, there is a homogeneous behaviour of the tourism factor (T) among countries. This factor drives energy consumption throughout the period, except during the financial crisis. Therefore, tourist activity increases energy consumption. However, its influence on energy consumption is compensated by the service level offered to the tourists, as the results show that the human capital intensity factor ( $L I)$ almost always has the opposite sign to the one shown by factor $T$. Thus, when the number of tourists increases, boosting electricity consumption, it seems that the services offered to tourists, that is, the level of customer service that can be offered to tourists, is reflected in the decrease of the number of hours worked by overnight stays. Therefore, it is acting as a compensating factor. This fact seems to be due either to the best preparation of the employees, which increases their efficiency, but may also be due to the reduction of services provided to tourists. It should be noted, however, that in no case, the $L I$ factor fully compensates for the effect of factor $T$. So, the growth of tourism activity has tended so far towards the growth of electricity consumption in the hospitality sector.

\subsection{Main results by countries.}

Finally, Table A.2 in the Annex shows the numerical values when performing an analysis for the 9 European countries by the five considered factors. Figure 3 shows these results by countries, displaying the evolution for the five considered factors in LMDI analysis (2004-2012) detailed for each country. 
Firstly, it may be highlighted that those countries with lesser tourism activity had a lesser influence on the energy consumption variation, implying that their behaviour had lesser influence on total energy consumption, but also that their behaviour had lesser influence on changes in their own sectoral energy use. Therefore, the results show that, Denmark, the Netherlands and Sweden are countries maintaining a certain homogeneity in the influence of the variables considered on energy consumption in hotels and restaurants. Likewise, these countries have little influence in the determination of the energy consumption of the total of the countries considered, since their capacity of tourist attraction is lower than that of the rest of the countries in the sample. It must be taken into account that these countries hold the positions 12, 14 and 22 in tourist destination.

On the contrary, the countries with higher tourism attraction had more variability on their results throughout the period, probably because they had been more affected by the crisis and the tourism evolution. Likewise, their hotels and restaurants energy consumption has been higher, and changes have higher influence. Nevertheless, although they had higher influence on energy consumption, the factors that drive or compensate the energy consumption in each country are different, reflecting the particularities of the sector of each country, and therefore the need to know the sector of each country to understand the drivers of energy consumption in the hospitality sector in each case.

In the case of Germany and the United Kingdom, there is an increase in the growth rates of energy consumption up to the crisis period, after which a certain tendency towards stabilization is observed. The energetic intensity (or energy inefficiency) acts as a driver or compensating factor according to the moment of the cycle, which seems to show the 
lack of capacity of the sector to adapt to the decrease or increase of activity quickly. This effect also seems to be shown in the case of Spain, since it shows that energy inefficiency is a clear driver of electricity consumption in certain periods. In this sense, it is worth noting that we are facing a sector that needs to properly condition large buildings. If the activity decreases, the conditioning needs remain the same, significantly increasing inefficiency. In this sense, the need to find heating and cooling systems of buildings (hotels, restaurants ...) that allow their conditioning by zones may be appropriate for those countries that may be faced with significant changes in activity, according to the global and local economy evolution.

Germany and the United Kingdom are the countries that show a greater variability in the effect of the other factors. There is a great variability in the factors associated with the production mode, implying that over the period they have seen their productive structures change in such a way that they have exerted a notable influence on the electric consumption of the sector. In Germany, the lack of capital investment after the crisis has contributed to the reduction of energy consumption, although once this phase is over, there is a rebound of capital investments that act boosting the energy consumption, once the tourism tends to grow again. On the contrary, in the UK, capital investments do not tend to increase after the crisis, and the evolution of tourism is compensated by employment. Thus, when tourism grows, it acts as a clear driver of energy consumption, but is compensated by a reduction in the service offered to the tourists, i.e. there is not an employment growth in line with the tourism growth. Therefore, the use of work becomes more energetically efficient. 
In the case of Spain, it seems that its evolution with respect to capital investments is similar to that of Germany, but with lesser effects on energy consumption. Regarding employment, the same effects are observed as in the UK, but also with less intensity.

With respect to Italy and France, they are countries that do not show such pronounced effects during the years of financial crisis. In Italy, there is a tendency to decelerate the growth of consumption in the sector, with gains in energy efficiency almost every year, and especially at the end of the period. This gain in efficiency has been acting as a clear compensatory factor. A slight variation of tourism and a decrease in the relative use of capital in the period can justify this behavior.

In France, fairly homogeneous values are observed throughout the period with the exception of the growth of energy inefficiency in a year of crisis, and the reverse behavior to recover. The important growth of tourism in 2010 should be noted, acting as an important driver of energy consumption, which is clearly offset, however, by the energy efficiency gained by the employment factor (LI).

Finally, in Portugal, the increase in the stock of capital has been a strong driver of electricity consumption at the beginning of the period, but its influence has tended to reduce since 2008. Likewise, it is also worth noting the improvement in energy efficiency throughout the period, which may explain the reduction of the energy consumption rates in this period.

\section{Insert Figure 3 here}

Figure 3. Evolution of the five factors considered in LMDI analysis (2004-2012) by countries. 


\section{Conclusions}

Tourist activity is valued worldwide by the multiple economic benefits in the countries of destination, and is measured through keeping a record of overnight stays and the demand of direct and indirect services of the different sub-sectors, among them hotels and restaurants, etc. However, it is important to evaluate their net benefits considering also the associated costs in terms of a greater impairment of the heritage, use of local natural resources or greater energy consumption.

In this sense, tourism activity must be analysed based on the environmental costs generated by it, and there is a wide variety of works that show that tourism has a significant impact on climate change and also needs to be considered from the viewpoint of energy consumption and $\mathrm{CO}_{2}$ emissions.

The relationships between Hotel and Restaurant electricity consumption and tourism growth during the period 2004-2012 have been analysed for Denmark, France, Germany, Italy, Holland, Portugal, Spain, Sweden and the United Kingdom.

The use of the log-mean Divisia index method (LMDI I) decomposition technique is then proposed to quantitatively evaluate the extent to which tourism activity and other productive factors affect or determine energy consumption in this sector, including energy intensity (EI), physical capital intensity $(K I)$, physical and human capital relationship $(K L)$, human capital intensity $(L I)$ and tourism activity $(T)$ as the decomposition factors or effects to be considered.

In accordance with the obtained results, a heterogeneous behavior of factors may be highlighted, inducing the electricity consumption throughout the period in question, being relevant the change in energy consumption around the financial crisis years and 
the significance of the tourism factor in explaining the evolution of electricity consumption.

Performing the analysis for the different countries by the five considered factors, it may be highlighted that countries with higher tourism attraction, since they have been more affected by the crisis in their tourism sector evolution, have experienced more variability in their results throughout the period.

The energetic intensity (or energy inefficiency) acts as a compensating factor according to the moment of the cycle, and the effect of this is particularly demonstrated in the cases of Germany, the United Kingdom and Spain. These three countries have also experienced great variability in the factors associated with the production mode in their tourism sector.

Finally, Italy and France do not seem to have such pronounced effects during the years of financial crisis, while in Portugal the stock of capital has been acting as a driver of electricity consumption.

\section{References}

Ang, B.W. (2004). Decomposition analysis for policymaking in energy: Which is the preferred method? Energy Policy, 32(9), 1131-1139.

Ang, B.W. (2005). The LMDI approach to decomposition analysis: A practical guide. Energy Policy, 33(7), 867-871.

Ang, B.W., \& Liu, N. (2007). Negative-value problems of the logarithmic mean Divisia index decomposition approach. Energy Policy 35(1), 739-742.

Becken, S., Frampton, C., \& Simmons, D. (2001). Energy consumption patterns in the accommodation sector — The New Zealand case. Ecological Economics, 39(3), 371-386. 
Becken, S., Simmons, D.G., \& Frampton, C. (2003). Energy use associated with different travel choices. Tourism Management, 24(3), 267-277.

Chong, C., Liu, P., Ma, L., Li, Z., Ni, W., Li, X., \& Song, S. (2017). LMDI decomposition of energy consumption in Guangdong Province, China, based on an energy allocation diagram. Energy, 133, 525-544.

Cortes-Jimenez, I., \& Pulina, M. (2010). Inbound tourism and long-run economic growth. Current Issues in Tourism, 13(1), 61-74.

Cruz, L., \& Dias, J. (2016). Energy and $\mathrm{CO}_{2}$ intensity changes in the EU-27: Decomposition into explanatory effects. Sustainable Cities and Society, 26, 486-495.

Dogan, E., \& Aslan, A. (2017). Exploring the relationship among $\mathrm{CO}_{2}$ emissions, real GDP, energy consumption and tourism in the EU and candidate countries: Evidence from panel models robust to heterogeneity and cross-sectional dependence. Renewable and Sustainable Energy Reviews, 77, 239-245.

Dong, B., Zhang, M., Mu, H., \& Su, X. (2016). Study on decoupling analysis between energy consumption and economic growth in Liaoning Province. Energy Policy, 97, 414-420.

Du, K., \& Lin, B. (2015). Understanding the rapid growth of China's energy consumption: A comprehensive decomposition framework. Energy, 90, 570-577.

Duran, E., Aravena, C., \& Aguilar, R. (2015). Analysis and decomposition of energy consumption in the Chilean industry. Energy Policy, 86, 552-561.

Ediger, V.Ş., \& Huvaz, O. (2006). Examining the sectoral energy use in Turkish economy (1980-2000) with the help of decomposition analysis. Energy Conversion and Management, 47(6), 732-745.

Enerdata (2018). Odyssee: European Energy Efficiency Database.Enerdata: Grenoble/London, France/UK.

http://www.indicators.odyssee-mure.eu/energy-efficiency-database.html

Eurostat (2018). Database. European Commission: Brussels, Belgium. http://ec.europa.eu/eurostat/data/database

Frantál, B., \& Urbánková, R. (2017). Energy tourism: An emerging field of study. Current Issues in Tourism, 20(13), 1395-1412. 
Goldemberg, J., \& Johansson, T.B. (Eds.) (2004). World Energy Assessment: Overview 2004 Update. UNDP, United Nations Development Programme, New York. http://www.leonardo-energy.org/world-energy-assessment-overview-2004-update

Gómez-Calero, M., Molina, J.A., \& Pablo-Romero, M.P. (2014). Research note: Exploring the effect of tourism on economic growth in the Spanish provinces and autonomous communities, 1999-2008. Tourism Economics, 20(5), 1117-1124.

Gössling, S. (2002). Global environmental consequences of tourism. Global Environmental Change, 12(4), 283-302.

International Panel on Climate Change (2014). Climate Change 2014 Synthesis Report.International Panel on Climate Change (IPCC),IPCC Secretariat: Geneva, Switzerland. http://www.ipcc.ch/report/ar5/syr/

Katirciogulu, S.T. (2014). International tourism, energy consumption and environmental pollution: The case of Turkey. Renewable and Sustainable Energy Reviews, 36, 180187.

Lima, F., Nunes, M.L., Cunha, J., \& Lucena, A.F.P. (2017). Driving forces for aggregate energy consumption: A cross-country approach. Renewable and Sustainable Energy Reviews, 68(Part 2), 1033-1050.

Liu, X., Zhou, D., Zhou, P., \& Wang, Q. (2018). Factors driving energy consumption in China: A joint decomposition approach. Journal of Cleaner Production, 172, 724734.

Moutinho, V., Madaleno, M., \& Silva, P.M. (2016). Which factors drive $\mathrm{CO}_{2}$ emissions in EU-15? Decomposition and innovative accounting. Energy Efficiency, 9(5), 10871113.

Naradda Gamage, S.K., Hewa Kuruppuge, R., \& Haq, I.U. (2017). Energy consumption, tourism development, and environmental degradation in Sri Lanka. Energy Sources, Part B: Economics, Planning, and Policy, 12(10), 910-916.

Nepal, R., al Irsyad, M.I., \& Nepal, S.K. (2019). Tourist arrivals, energy consumption and pollutant emissions in a developing economy-implications for sustainable tourism. Tourism Management, 72, 145-154.

Nižić, K.M., Grdić, Z.S., \& Hustić, A. (2016). The importance of energy for the tourism sector. Academica Turistica, 9(2), 77-83. 
Olanrewaju, O.A., Jimoh, A.A., \& Kholopane, P.A. (2012). Integrated IDA-ANN-DEA for assessment and optimization of energy consumption in industrial sectors. Energy, 46(1), 629-635.

Pablo-Romero, M.P., Pozo-Barajas, R., \& Sánchez-Rivas, J. (2017a). Relationships between tourism and hospitality sector electricity consumption in Spanish provinces (1999-2013). Sustainability, 9(4), 480.

Pablo-Romero, M.P., \& Sánchez-Braza, A. (2015). Productive energy use and economic growth: Energy, physical and human capital relationships. Energy Economics, 49, $420-429$.

Pablo-Romero, M.P., Sánchez-Braza, A., \& Sánchez-Rivas, J. (2017b). Relationships between hotel and restaurant electricity consumption and tourism in 11 European Union countries. Sustainability 9(11), 2109.

Robaina-Alves, M., Moutinho, V., \& Costa, R. (2016). Change in energy-related $\mathrm{CO}_{2}$ (carbon dioxide) emissions in Portuguese tourism: a decomposition analysis from 2000 to 2008. Journal of cleaner production, 111, 520-528.

Rutty, M., Gössling, S., Scott, D., \& Hall, C.M. (2015). The global effects and impacts of tourism: An overview. In The Routledge Handbook of Tourism and Sustainability; Hall, C.M., Gössling, S., Scott, D., Eds.; Routledge: Abingdon, UK, 2015; pp.36-63.

Saidi, K., \& Hammami, S. (2015). The impact of $\mathrm{CO}_{2}$ emissions and economic growth on energy consumption in 58 countries. Energy Reports, 1, 62-70.

Scott, D., Hall, C.M., \& Gössling, S. (2016a). A review of the IPCC Fifth Assessment and implications for tourism sector climate resilience and decarbonization. Journal of Sustainable Tourism, 24(1), 8-30.

Scott, D., Hall, C.M., \& Gössling, S. (2016b). A report on the Paris Climate Change Agreement and its implications for tourism: Why we will always have Paris. Journal of Sustainable Tourism, 24(7), 933-948.

Scott, D., Gössling, S., Hall, C.M., \& Peeters, P. (2016). Can tourism be part of the decarbonized global economy?: The costs and risks of alternate carbon reduction policy pathways. Journal of Sustainable Tourism, 24(1), 52-72. 
United Nations (2015). Adoption of the Paris agreement - COP21. Paris, United Nations Framework Convention on Climate Change.

http://unfccc.int/files/essential_background/convention/application/pdf/english_paris agreement.pdf.

United Nations World Tourism Organization (2017). Tourism Highlights, 2017 Edition. United Nations World Tourism Organization (UNWTO): Madrid, Spain. http://mkt.unwto.org/publication/unwto-tourism-highlights

Voigt, S., De Cian, E., Schymura, M., \& Verdolini, E. (2014). Energy intensity developments in 40 major economies: Structural change or technology improvement? Energy Economics, 41, 47-62.

Wang, Y., Ge, X., Liu, J., \& Ding, Z. (2016). Study and analysis of energy consumption and energy-related carbon emission of industrial in Tianjin, China. Energy Strategy Reviews, 10, 18-28.

WIOD (2018). World Input-Output Database.WIOD, European Commission Brussels, Belgium. www.wiod.org

World Travel \& Tourism Council (2017). Travel \& Tourism Economic Impact 2017 North America. World Travel \& Tourism Council (WWTC): London, UK. https://www.wttc.org/research/economic-research/economic-impactanalysis/regional-reports/

$\mathrm{Wu}$, Y. (2012). Energy intensity and its determinants in China's regional economies. Energy Policy, 41, 703-711.

Zhang, M., Song, Y., Li, P., \& Li, H. (2016). Study on affecting factors of residential energy consumption in urban and rural Jiangsu. Renewable and Sustainable Energy Reviews, 53, 330-337. 
Annex

Table A.1. Main figures for factors considered in LMDI analysis 2004-2012 by countries $2004-2005 \quad 2005-2006 \quad 2006-2007 \quad 2007-2008 \quad 2008-2009 \quad 2009-2010 \quad 2010-2011 \quad 2011-2012$

\begin{tabular}{|c|c|c|c|c|c|c|c|c|}
\hline \multirow{2}{*}{$\frac{E I_{i}=E_{i} / V A B_{i}}{\text { Denmark }}$} & \multicolumn{8}{|c|}{$\Delta E I$ (Energy Intensity Factor) } \\
\hline & -0.047051 & 5.893930 & -1.146079 & 0.798035 & 4.479508 & 11.306404 & 2.377621 & -9.082396 \\
\hline France & 4.605857 & 5.843456 & 3.966217 & 18.491706 & 70.302400 & -83.695577 & -8.523175 & 14.117702 \\
\hline Germany & -136.787579 & -25.955790 & -128.931742 & 174.492033 & 275.424148 & 36.540023 & -121.667577 & -13.818188 \\
\hline Italy & 23.542901 & -10.719968 & -9.720244 & 5.024195 & 20.159507 & -2.120936 & -48.879035 & -50.696469 \\
\hline Netherlands & 19.904107 & -15.039842 & -14.703091 & 2.631618 & 21.928089 & 33.640439 & 1.581710 & 14.190341 \\
\hline Portugal & -3.421651 & -5.753133 & -20.807423 & 24.736953 & -3.054732 & -30.328786 & -21.638048 & -22.080856 \\
\hline Spain & 66.983738 & -3.606902 & 118.169575 & 0.899818 & 190.417565 & -21.067346 & -1.685758 & 18.294178 \\
\hline Sweden & 5.454694 & -2.621816 & 5.879005 & -2.921062 & 8.723576 & -1.491433 & 3.743783 & -3.151382 \\
\hline United Kingdom & -33.501006 & -47.065077 & -161.356934 & 47.494082 & 161.920460 & -28.319362 & -7.974743 & -15.236001 \\
\hline$\sum \Delta E \boldsymbol{I}_{i}$ & -53.265992 & -99.025141 & -208.650716 & 271.647376 & 750.300522 & -85.536573 & -202.665220 & -67.463072 \\
\hline \multicolumn{9}{|c|}{$K I_{i}=V A B_{i} / K_{i} \quad \Delta K I$ (Physical Capital Intensity Factor) } \\
\hline Denmark & 0.232305 & 3.218749 & 0.837270 & 2.477001 & -1.862371 & -2.783484 & 5.148675 & 3.308103 \\
\hline France & -4.295823 & -15.226944 & -1.572031 & -32.630134 & -21.482095 & 38.862134 & 20.338292 & -8.259711 \\
\hline Germany & 9.432555 & 2.485094 & 26.773448 & -48.511869 & -81.442902 & 28.848539 & 32.916051 & 23.062801 \\
\hline Italy & -8.404786 & -2.776592 & -1.122179 & -50.321631 & -3.122338 & -48.169213 & -13.511066 & -5.126347 \\
\hline Netherlands & -0.749008 & 1.396490 & 4.531941 & -16.246270 & -9.545989 & -3.925954 & 12.382450 & 4.052460 \\
\hline Portugal & 7.777262 & -85.555821 & -67.571229 & -29.363450 & 5.291978 & -1.328963 & -0.514043 & -0.412479 \\
\hline Spain & -12.981910 & -7.262281 & -8.589220 & 8.554131 & 15.420580 & 1.536625 & 8.852980 & 8.460454 \\
\hline Sweden & 2.586693 & 2.553483 & 2.256510 & -5.651866 & -15.361442 & 5.297155 & 10.727777 & 9.765252 \\
\hline United Kingdom & -40.261137 & -7.383456 & -24.328958 & -49.048755 & -31.119708 & 20.843236 & 11.777694 & 63.295610 \\
\hline$\sum \Delta K I_{i}$ & -46.663850 & -108.551280 & -68.784448 & -220.742843 & -143.224288 & 39.180075 & 88.118809 & 98.146142 \\
\hline
\end{tabular}

\begin{tabular}{ccccccccc}
\hline $\boldsymbol{K} \boldsymbol{L}_{i}=\boldsymbol{K}_{i} / \boldsymbol{L}_{i}$ & \multicolumn{1}{c}{$\boldsymbol{\Delta} \boldsymbol{K}$ (Physical and Human Capital Relationship Factor) } & & & \\
\hline Denmark & -3.793167 & -1.750123 & -1.686367 & -4.760756 & 0.856878 & 2.900256 & -2.436783 & -4.160256 \\
France & 4.036540 & 19.323460 & -5.726814 & 20.897275 & 15.702941 & -41.311839 & 11.252922 & -0.863335 \\
Germany & -29.925795 & -24.488372 & 20.828889 & -6.055928 & -61.896445 & -109.976358 & 67.748024 & 9.724156 \\
Italy & 11.422233 & -45.042009 & -23.344297 & 3.580788 & 21.770225 & 53.849217 & 10.865774 & -39.306516 \\
Netherlands & 3.609883 & -2.499878 & -6.640495 & -0.578335 & -11.501856 & -14.864752 & -14.904952 & -8.393852 \\
Portugal & -11.560838 & 84.192502 & 64.262594 & 19.630108 & 1.384916 & 10.440962 & 7.695193 & 12.193689 \\
Spain & -6.715352 & -7.345396 & -7.792981 & -18.685341 & -21.399876 & 10.660877 & -7.727584 & 19.412256 \\
Sweden & 2.683318 & -5.793341 & -1.208577 & 1.747067 & 8.649835 & -14.697849 & -10.377334 & -12.308142 \\
United Kingdom & 75.414168 & 26.238667 & 38.184345 & 40.666336 & 14.190056 & 5.597340 & 3.926810 & -65.912946 \\
\hline \multirow{2}{\Sigma}{$\Delta \boldsymbol{K} \boldsymbol{L}_{\boldsymbol{i}}$} & $\mathbf{4 5 . 1 7 0 9 9 2}$ & $\mathbf{4 2 . 8 3 5 5 0 9}$ & $\mathbf{7 6 . 8 7 6 2 9 7}$ & $\mathbf{5 6 . 4 4 1 2 1 3}$ & $\mathbf{- 3 2 . 2 4 3 3 2 6}$ & $\mathbf{- 9 7 . 4 0 2 1 4 7}$ & $\mathbf{6 6 . 0 4 2 0 6 9}$ & $\mathbf{- 8 9 . 6 1 4 9 4 6}$ \\
\hline
\end{tabular}




\begin{tabular}{|c|c|c|c|c|c|c|c|c|}
\hline \multirow{2}{*}{$\begin{array}{c}L I_{i}=L_{i} / T u r_{i} \\
\text { Denmark }\end{array}$} & \multicolumn{8}{|c|}{$\Delta L I$ (Human Capital Intensity Factor) } \\
\hline & 3.400335 & 0.505333 & 0.289435 & 1.570976 & -0.152517 & -3.008771 & 2.030983 & 0.389467 \\
\hline France & -20.865719 & 4.585016 & 20.102204 & 16.017376 & 5.628492 & -231.562111 & -6.283943 & 6.164418 \\
\hline Germany & -4.688463 & -10.274786 & 185.888037 & -8.182602 & 64.527788 & -31.707337 & -63.187865 & -40.733654 \\
\hline Italy & -23.259847 & 45.332491 & 26.550858 & 60.082965 & -20.497375 & -17.301595 & -19.741800 & 51.235318 \\
\hline Netherlands & -0.432180 & -5.612855 & -5.491708 & 14.573866 & -1.054509 & 4.138934 & 9.457487 & 4.273775 \\
\hline Portugal & 0.430231 & -2.375123 & -5.282821 & 7.395775 & 8.450451 & -1.479538 & -11.883410 & -9.471195 \\
\hline Spain & 14.508840 & -1.011438 & 15.392358 & 18.162932 & 26.847478 & -49.705955 & -37.604975 & -24.723069 \\
\hline Sweden & -7.212719 & -1.545884 & 0.526479 & 12.381111 & -4.328900 & 9.523821 & 4.333665 & 5.222935 \\
\hline United Kingdom & -173.060835 & 82.089979 & 31.320114 & 24.649698 & -72.646021 & 99.487042 & 17.360376 & -237.471579 \\
\hline$\sum \Delta L I_{i}$ & -211.180357 & 111.692734 & 269.294957 & 146.652098 & 6.774889 & -221.615511 & -105.519482 & -245.113583 \\
\hline $\boldsymbol{T}_{i}$ & $\Delta T$ (Touris & m Factor) & & & & & & \\
\hline Denmark & 3.400335 & 0.505333 & 0.289435 & 1.570976 & -0.152517 & -3.008771 & 2.030983 & 0.389467 \\
\hline France & -20.865719 & 4.585016 & 20.102204 & 16.017376 & 5.628492 & -231.562111 & -6.283943 & 6.164418 \\
\hline Germany & -4.688463 & -10.274786 & 185.888037 & -8.182602 & 64.527788 & -31.707337 & -63.187865 & -40.733654 \\
\hline Italy & -23.259847 & 45.332491 & 26.550858 & 60.082965 & -20.497375 & -17.301595 & -19.741800 & 51.235318 \\
\hline Netherlands & -0.432180 & -5.612855 & -5.491708 & 14.573866 & -1.054509 & 4.138934 & 9.457487 & 4.273775 \\
\hline Portugal & 0.430231 & -2.375123 & -5.282821 & 7.395775 & 8.450451 & -1.479538 & -11.883410 & -9.471195 \\
\hline Spain & 14.508840 & -1.011438 & 15.392358 & 18.162932 & 26.847478 & -49.705955 & -37.604975 & -24.723069 \\
\hline Sweden & -7.212719 & -1.545884 & 0.526479 & 12.381111 & -4.328900 & 9.523821 & 4.333665 & 5.222935 \\
\hline United Kingdom & -173.060835 & 82.089979 & 31.320114 & 24.649698 & -72.646021 & 99.487042 & 17.360376 & -237.471579 \\
\hline$\sum \Delta \boldsymbol{T}_{i}$ & -211.180357 & 111.692734 & 269.294957 & 146.652098 & 6.774889 & -221.615511 & -105.519482 & -245.113583 \\
\hline
\end{tabular}


Table A.2. Main figures for countries considered in LMDI analysis 2004-2012 detailed by factors 2004-2005 2005-2006 2006-2007 2007-2008 2008-2009 2009-2010 2010-2011 $2011-2012$

\section{Denmark}

\begin{tabular}{ccccccccc}
\hline$\Delta \boldsymbol{E} \boldsymbol{I}$ & -0.047051 & 5.893930 & -1.146079 & 0.798035 & 4.479508 & 11.306404 & 2.377621 & 14.117702 \\
$\Delta \boldsymbol{K} \boldsymbol{I}$ & 0.232305 & 3.218749 & 0.837270 & 2.477001 & -1.862371 & -2.783484 & 5.148675 & -8.259711 \\
$\Delta \boldsymbol{K} \boldsymbol{L}$ & -3.793167 & -1.750123 & -1.686367 & -4.760756 & 0.856878 & 2.900256 & -2.436783 & -0.863335 \\
$\Delta \boldsymbol{L} \boldsymbol{I}$ & 3.400335 & 0.505333 & 0.289435 & 1.570976 & -0.152517 & -3.008771 & 2.030983 & 6.164418 \\
$\Delta \boldsymbol{T}$ & 0.207579 & 2.132111 & 1.705740 & -0.085256 & -3.321498 & 1.585595 & 2.879505 & -1.159075 \\
\hline$\Delta \boldsymbol{E}$ & $\mathbf{0 . 0 0}$ & $\mathbf{1 0 . 0 0}$ & $\mathbf{0 . 0 0}$ & $\mathbf{0 . 0 0}$ & $\mathbf{0 . 0 0}$ & $\mathbf{1 0 . 0 0}$ & $\mathbf{1 0 . 0 0}$ & $\mathbf{1 0 . 0 0}$ \\
\hline
\end{tabular}

\section{France}

\begin{tabular}{ccccccccc}
\hline$\Delta \boldsymbol{E} \boldsymbol{I}$ & 4.605857 & 5.843456 & 3.966217 & 18.491706 & 70.302400 & -83.695577 & -8.523175 & 14.117702 \\
$\Delta \boldsymbol{K} \boldsymbol{I}$ & -4.295823 & -15.226944 & -1.572031 & -32.630134 & -21.482095 & 38.862134 & 20.338292 & -8.259711 \\
$\Delta \boldsymbol{K} \boldsymbol{L}$ & 4.036540 & 19.323460 & -5.726814 & 20.897275 & 15.702941 & -41.311839 & 11.252922 & -0.863335 \\
$\Delta \boldsymbol{L} \boldsymbol{I}$ & -20.865719 & 4.585016 & 20.102204 & 16.017376 & 5.628492 & -231.562111 & -6.283943 & 6.164418 \\
$\Delta \boldsymbol{T}$ & 36.519144 & 5.475012 & 13.230425 & -2.776223 & -20.151738 & 267.707393 & 23.215904 & -1.159075 \\
\hline$\Delta \boldsymbol{E}$ & $\mathbf{2 0 . 0 0}$ & $\mathbf{2 0 . 0 0}$ & $\mathbf{3 0 . 0 0}$ & $\mathbf{2 0 . 0 0}$ & $\mathbf{5 0 . 0 0}$ & $\mathbf{- 5 0 . 0 0}$ & $\mathbf{4 0 . 0 0}$ & $\mathbf{1 0 . 0 0}$ \\
\hline
\end{tabular}

\section{Germany}

\begin{tabular}{|c|c|c|c|c|c|c|c|c|}
\hline$\Delta E I$ & -136.787579 & -25.955790 & -128.931742 & 174.492033 & 275.424148 & 36.540023 & -121.667577 & -13.818188 \\
\hline$\Delta K I$ & 9.432555 & 2.485094 & 26.773448 & -48.511869 & -81.442902 & 28.848539 & 32.916051 & 23.062801 \\
\hline$\Delta K L$ & -29.925795 & -24.488372 & 20.828889 & -6.055928 & -61.896445 & -109.976358 & 67.748024 & 9.724156 \\
\hline$\Delta \boldsymbol{L I}$ & -4.688463 & -10.274786 & 185.888037 & -8.182602 & 64.527788 & -31.707337 & -63.187865 & -40.733654 \\
\hline$\Delta \boldsymbol{T}$ & 21.969282 & 28.233855 & -134.558632 & 28.258366 & -46.612589 & 56.295132 & 64.191366 & 51.764884 \\
\hline$\Delta \boldsymbol{E}$ & -140.00 & -30.00 & -30.00 & 140.00 & 150.00 & -20.00 & -20.00 & 30.00 \\
\hline \multicolumn{9}{|l|}{ Italy } \\
\hline$\Delta E I$ & 23.542901 & -10.719968 & -9.720244 & 5.024195 & 20.159507 & -2.120936 & -48.879035 & -50.696469 \\
\hline$\Delta K I$ & -8.404786 & -2.776592 & -1.122179 & -50.321631 & -3.122338 & -48.169213 & -13.511066 & -5.126347 \\
\hline$\Delta K L$ & 11.422233 & -45.042009 & -23.344297 & 3.580788 & 21.770225 & 53.849217 & 10.865774 & -39.306516 \\
\hline$\Delta \boldsymbol{L I}$ & -23.259847 & 45.332491 & 26.550858 & 60.082965 & -20.497375 & -17.301595 & -19.741800 & 51.235318 \\
\hline$\Delta \boldsymbol{T}$ & 26.699499 & 33.206077 & 27.635861 & -8.366317 & -8.310018 & 13.742527 & 31.266127 & -16.105985 \\
\hline$\Delta \boldsymbol{E}$ & 30.00 & 20.00 & 20.00 & 10.00 & 10.00 & 0.00 & -40.00 & -60.00 \\
\hline \multicolumn{9}{|c|}{ Netherlands } \\
\hline$\Delta E I$ & 19.904107 & -15.039842 & -14.703091 & 2.631618 & 21.928089 & 33.640439 & 1.581710 & 14.190341 \\
\hline$\Delta K I$ & -0.749008 & 1.396490 & 4.531941 & -16.246270 & -9.545989 & -3.925954 & 12.382450 & 4.052460 \\
\hline$\Delta K L$ & 3.609883 & -2.499878 & -6.640495 & -0.578335 & -11.501856 & -14.864752 & -14.904952 & -8.393852 \\
\hline$\Delta \boldsymbol{L I}$ & -0.432180 & -5.612855 & -5.491708 & 14.573866 & -1.054509 & 4.138934 & 9.457487 & 4.273775 \\
\hline$\Delta \boldsymbol{T}$ & -2.332802 & 11.756084 & 12.303353 & -10.380878 & 0.174264 & 1.011333 & 1.483306 & -4.122724 \\
\hline$\Delta \boldsymbol{E}$ & 20.00 & -10.00 & -10.00 & -10.00 & 0.00 & 20.00 & 10.00 & 10.00 \\
\hline
\end{tabular}




\section{Portugal}

\begin{tabular}{|c|c|c|c|c|c|c|c|c|}
\hline$\Delta E I$ & -3.421651 & -5.753133 & -20.807423 & 24.736953 & -3.054732 & -30.328786 & -21.638048 & -22.080856 \\
\hline$\Delta K I$ & 7.777262 & -85.555821 & -67.571229 & -29.363450 & 5.291978 & -1.328963 & -0.514043 & -0.412479 \\
\hline$\Delta K L$ & -11.560838 & 84.192502 & 64.262594 & 19.630108 & 1.384916 & 10.440962 & 7.695193 & 12.193689 \\
\hline$\Delta \boldsymbol{L I}$ & 0.430231 & -2.375123 & -5.282821 & 7.395775 & 8.450451 & -1.479538 & -11.883410 & -9.471195 \\
\hline$\Delta \boldsymbol{T}$ & 6.774997 & 9.491576 & 9.398878 & -2.399385 & -12.072614 & 2.696325 & 6.340308 & -0.229158 \\
\hline$\Delta \boldsymbol{E}$ & 0.00 & 0.00 & -20.00 & 20.00 & 0.00 & -20.00 & -20.00 & -20.00 \\
\hline \multicolumn{9}{|c|}{ Spain } \\
\hline$\Delta E I$ & 66.983738 & -3.606902 & 118.169575 & 0.899818 & 190.417565 & -21.067346 & -1.685758 & 18.294178 \\
\hline$\Delta K I$ & -12.981910 & -7.262281 & -8.589220 & 8.554131 & 15.420580 & 1.536625 & 8.852980 & 8.460454 \\
\hline$\Delta K L$ & -6.715352 & -7.345396 & -7.792981 & -18.685341 & -21.399876 & 10.660877 & -7.727584 & 19.412256 \\
\hline$\Delta \boldsymbol{L I}$ & 14.508840 & -1.011438 & 15.392358 & 18.162932 & 26.847478 & -49.705955 & -37.604975 & -24.723069 \\
\hline$\Delta \boldsymbol{T}$ & 8.204684 & 19.226017 & 2.820269 & -8.931540 & -41.285746 & 28.575799 & 38.165337 & -11.443818 \\
\hline$\Delta \boldsymbol{E}$ & 70.00 & 0.00 & 120.00 & 0.00 & 170.00 & -30.00 & 0.00 & 10.00 \\
\hline \multicolumn{9}{|c|}{ Sweden } \\
\hline$\Delta E \boldsymbol{I}$ & 5.454694 & -2.621816 & 5.879005 & -2.921062 & 8.723576 & -1.491433 & 3.743783 & -3.151382 \\
\hline$\Delta K I$ & 2.586693 & 2.553483 & 2.256510 & -5.651866 & -15.361442 & 5.297155 & 10.727777 & 9.765252 \\
\hline$\Delta K L$ & 2.683318 & -5.793341 & -1.208577 & 1.747067 & 8.649835 & -14.697849 & -10.377334 & -12.308142 \\
\hline$\Delta \boldsymbol{L I}$ & -7.212719 & -1.545884 & 0.526479 & 12.381111 & -4.328900 & 9.523821 & 4.333665 & 5.222935 \\
\hline$\Delta \boldsymbol{T}$ & 6.488014 & 7.407558 & 2.546584 & -5.555250 & 2.316931 & 1.368307 & 1.572109 & 0.471337 \\
\hline$\Delta \boldsymbol{E}$ & 10.00 & 0.00 & 10.00 & 0.00 & 0.00 & 0.00 & 10.00 & 0.00 \\
\hline
\end{tabular}

\section{United Kingdom}

\begin{tabular}{ccccccccc}
\hline$\Delta \boldsymbol{E} \boldsymbol{I}$ & -33.501006 & -47.065077 & -161.356934 & 47.494082 & 161.920460 & -28.319362 & -7.974743 & -15.236001 \\
$\Delta \boldsymbol{K} \boldsymbol{I}$ & -40.261137 & -7.383456 & -24.328958 & -49.048755 & -31.119708 & 20.843236 & 11.777694 & 63.295610 \\
$\Delta \boldsymbol{K} \boldsymbol{L}$ & 75.414168 & 26.238667 & 38.184345 & 40.666336 & 14.190056 & 5.597340 & 3.926810 & -65.912946 \\
$\Delta \boldsymbol{L} \boldsymbol{I}$ & -173.060835 & 82.089979 & 31.320114 & 24.649698 & -72.646021 & 99.487042 & 17.360376 & -237.471579 \\
$\Delta \boldsymbol{T}$ & 181.408809 & -53.880113 & -13.818568 & -33.761361 & 37.655212 & -107.608255 & -15.090137 & 265.324917 \\
\hline$\Delta \boldsymbol{E}$ & $\mathbf{1 0 . 0 0}$ & $\mathbf{0 . 0 0}$ & $\mathbf{- 1 3 0 . 0 0}$ & $\mathbf{3 0 . 0 0}$ & $\mathbf{1 1 0 . 0 0}$ & $\mathbf{- 1 0 . 0 0}$ & $\mathbf{1 0 . 0 0}$ & $\mathbf{1 0 . 0 0}$ \\
\hline
\end{tabular}




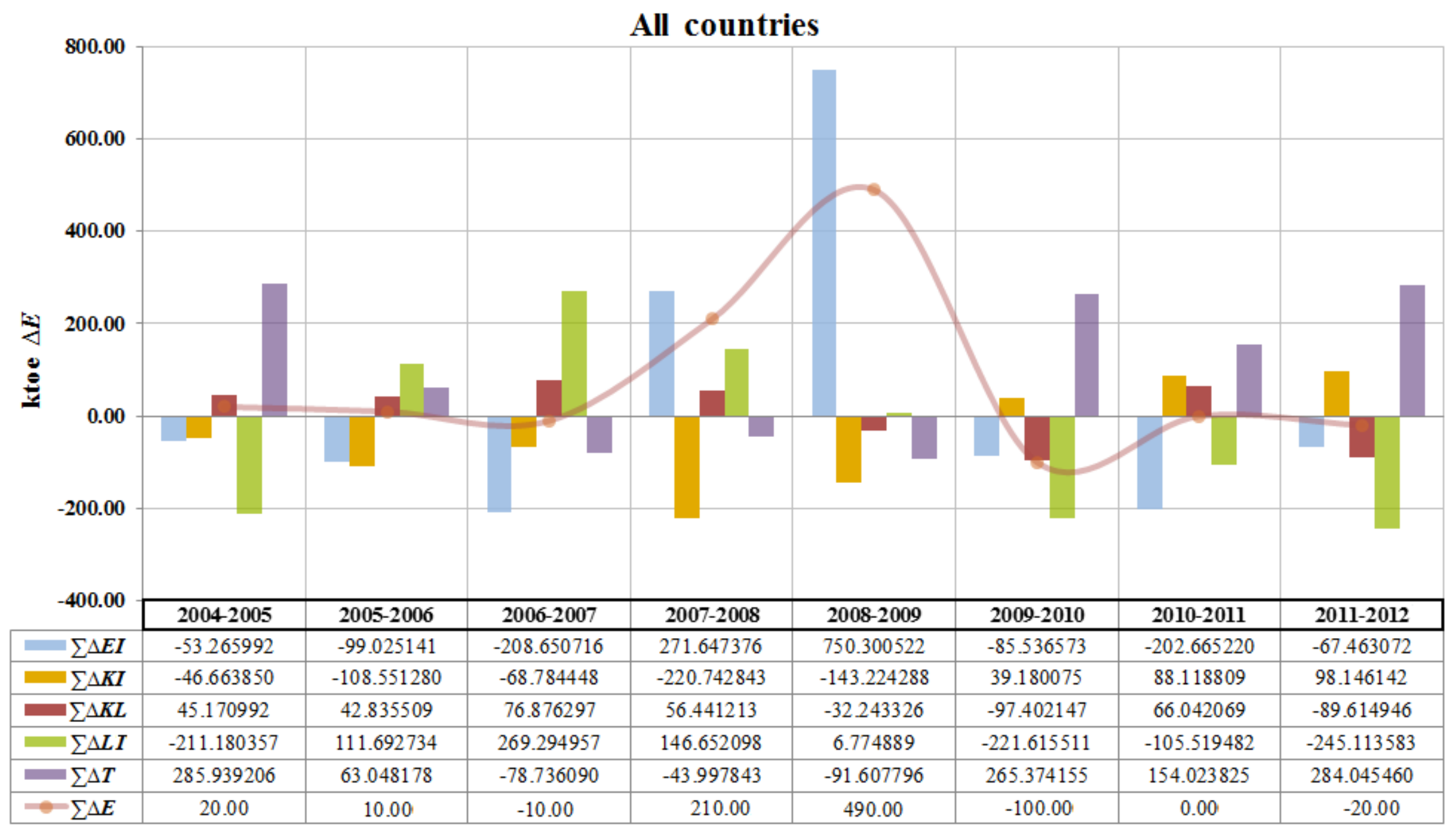

Figure 1. Main figures for factors considered in LMDI analysis 2004-2012 for all countries. 


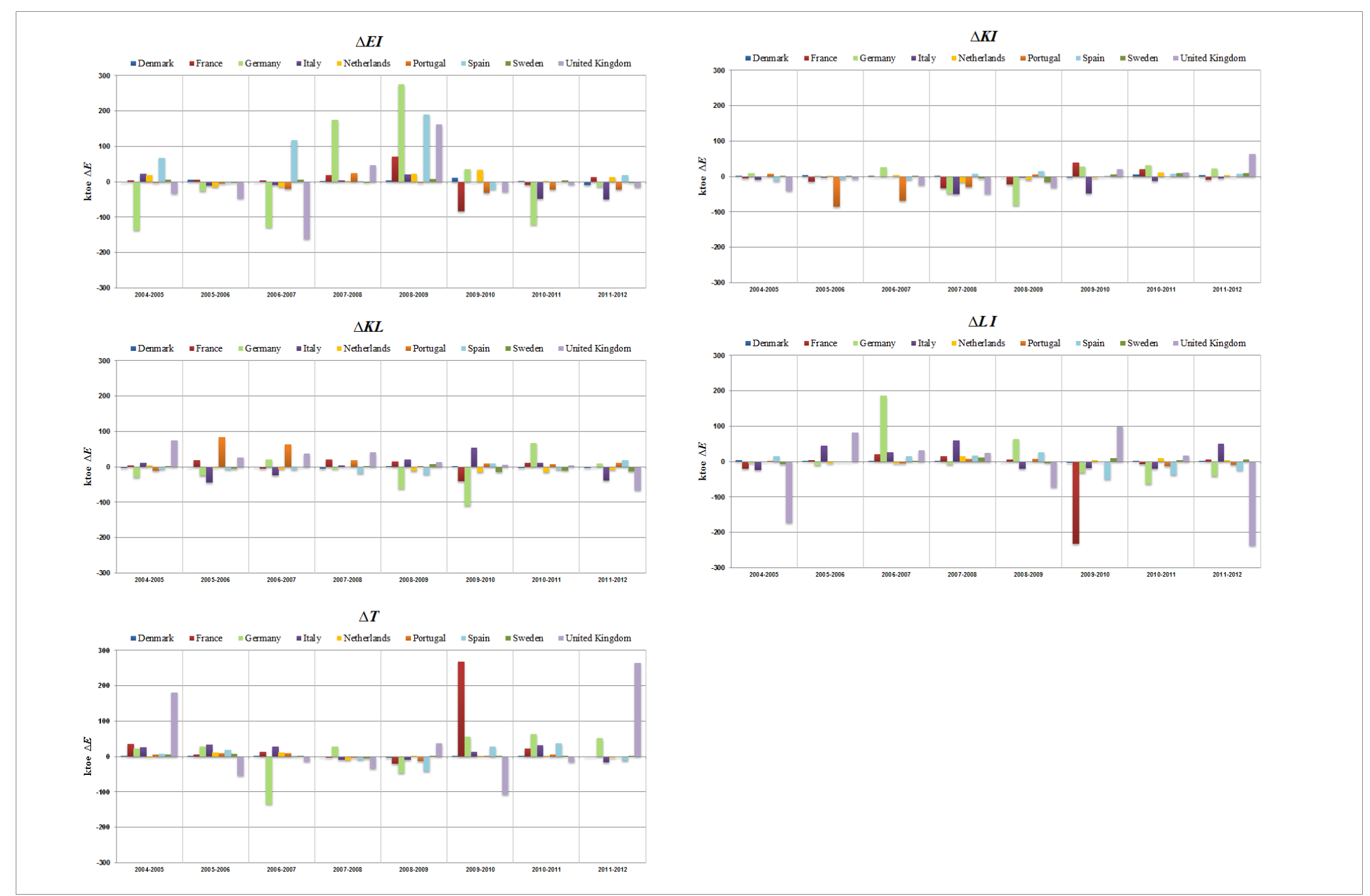

Figure 2. Main figures for factors considered in LMDI analysis 2004-2012 detailed by countries. 


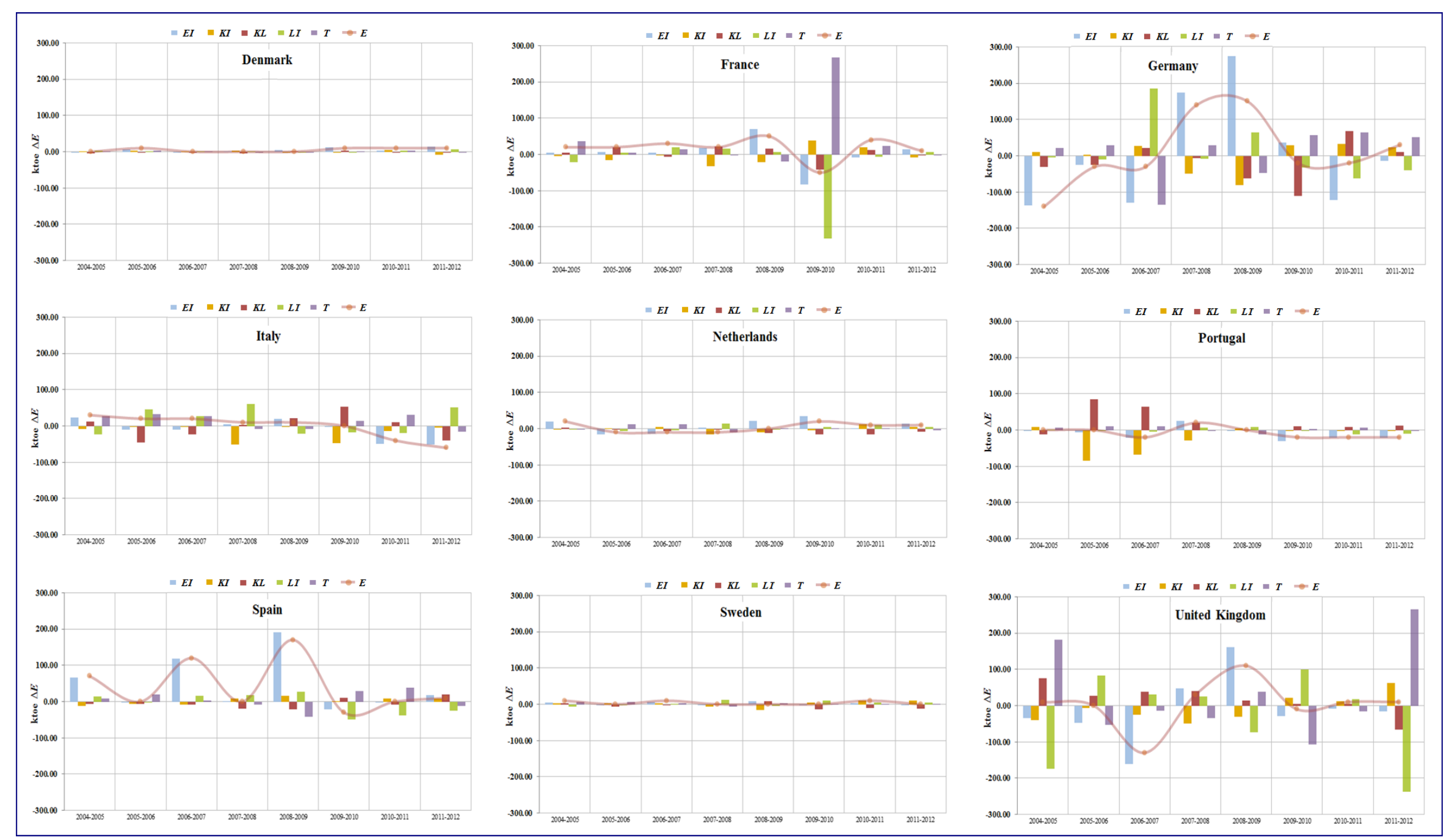

Figure 3. Evolution of the five factors considered in LMDI analysis (2004-2012) by countries. 